\title{
Observation and assessment of crossing situations between pleasure craft and a small passenger ferry
}

\author{
Kjell Ivar Øvergård ${ }^{1}$ (D) $\cdot$ Marius Stian Tannum ${ }^{2} \cdot$ Per Haavardtun $^{3}$
}

Received: 4 September 2019 / Accepted: 23 June 2020/Published online: 6 July 2020

(C) The Author(s) 2020

\begin{abstract}
A study of navigational situations involving a small passenger ferry 'Ole III' was conducted based on participatory observations in the Husøysund strait in Tønsberg municipality, Norway. The aims were to document the extent to which crossing situations are solved according to navigational rules and practice, and to investigate the number of incidents which could pose a risk for Ole III and its passengers. Because of the high density of private pleasure craft, we expected a rather large number of non-compliance with navigational rules. Observations supported this assumption, and based on the total of 3152 crossings with Ole III where other vessels where present, a total of $279(8.9 \%)$ incidents were considered to involve non-compliance with navigational rules and practice. A total of 165 incidents were caused by the other vessels failing to give way even though it had Ole III on its starboard side. This indicates that, at least in Norway, we may routinely expect pleasure craft to deviate from navigational rules for crossing situations. A number of incidents could partly be explained by a mismatch in understandings of which vessel had the right-ofway. Also, incident risk was higher when Ole III used active control strategies to handle crossing situations (e.g. keeping course and speed) as compared with passive control strategies. A taxonomy of situations based upon intentions is presented together with suggestions for control strategies for small passenger vessels that operate in waters with many pleasure craft.
\end{abstract}

Keywords Component · Unmanned · Passenger ferries · Navigation · Control strategies

Kjell Ivar Øvergård

koe@usn.no

1 Department of Health-, Social-, and Welfare Studies, University of South-Eastern Norway, Postboks 4, 3199 Borre, Norway

2 Department of Micro Systems, University of South-Eastern Norway, Postboks 4, 3199 Borre, Norway

3 Department of Maritime Operations, University of South-Eastern Norway, Postboks 4, 3199 Borre, Norway 


\section{Introduction}

Many rivers and narrow passageways that are transited by small passenger ferries are also used by a large number of pleasure craft and other small vessels. A small passenger ferry is defined in Norwegian regulations as a ship of less than $24 \mathrm{~m}$ that carries 12 or fewer passengers (Nærings- og Fiskeridepartementet 2020). Pleasure craft impose an extra risk for small passenger vessels. It has been documented that pleasure craft are involved in a considerable number of accidents (Mohovic and Baric 2013), and they might also pose a risk to commercial vessels due to their sometimes unpredictable behaviour (Porathe 2015). Additionally, pleasure craft skippers may also have an increased prevalence of sailing while intoxicated and/or to sail at excessive speeds (Norwegian Maritime Authority 2012). As accident investigations or near-miss assessments are seldom done for pleasure craft, little is documented about how these small passenger ferries interact with pleasure craft (Stoop 2003). A few recent reports do exist (Norwegian Maritime Authority 2012; AIBN 2019a, b), but these reports do not investigate near-misses and incidents, nor do they investigate the handling and resolution of crossing situations. In other words, there is a need for investigations on the types of situations that arise during crossing situation between pleasure craft and other commercial vessels.

Risk assessment of socio-technical systems is challenging as it includes human behaviour and the unpredictability inherent in modelling human agents. Current methods for risk management are based upon two types of data: (1) accident investigations and (2) reports of unwanted incidents (Mazaheri et al. 2018). Despite the underreporting of maritime accidents (Hassel et al. 2011), these methods for risk management have contributed great improvements in the technical side of modern sociotechnical systems, to the extent that the majority of accidents are attributed to human error (Dhillon 2007; Reason 1997; Dekker 2006). The main idea behind risk management is to identify human errors and equipment and components that are not working as intended, and then correcting these to prevent reoccurrence (Strauch 2005; Reason 1997; but see also Dekker 2006; Øvergård 2015). Risk management according to this model is the handling of non-events, that is, avoiding the presence of some (unwanted) phenomena (Hollnagel 2014). However, the focus on 'non-events' has an inherent paradox - as risk management improves, there will be less data to guide future risk management because there are fewer incidents or accidents (Mazaheri et al. 2018; Hollnagel 2013).

\section{Management of risk in socio-technical systems}

As a partial answer to this problem, Hollnagel $(2013,2014,2018)$ has suggested that risk management should rather focus on (1) work tasks that are handled successfully and (2) how routine situations are being performed and handled. Hollnagel (2018) claims that the advantage of focussing on route work and successes is that we will have a much larger data set that can guide risk management as there are more successes than failures. Additionally, information about how routine work is being done will provide us with better information to redesign systems (Hollnagel 2018). Still, information about routine work is not necessarily sufficient to support crew and system 
manufacturers as accidents, incidents and near-misses often are a result of unexpected deviations from routine operations (Bjørkli et al. 2007; Øvergård et al. 2015a). Also, the events that lead to deviations from routine operation are not necessarily under control by the crew aboard a vessel and these events might not be predictable.

An intermediate approach (which this article adheres to) aims to solve some of the above-mentioned challenges by focusing on the precursors to both normal operations and to near-misses, and then investigates how these incidents are handled or resolved (Øvergård et al. 2015a; Mazaheri et al. 2018). This approach partially comes out of Petersen's (2004) control situations framework (see also Bjørkli et al. 2007). Within this framework, incidents are 'situations where conditions and actions produce a situation that under slightly different circumstances would have turned into an accident with a large loss probability' (Øvergård et al. 2015a, p. 367). In principle, we can say that incidents or near-misses are cases that would have gone wrong had it not been for the intervention of a human or an automaton (Mazaheri et al. 2018). Near-misses have similar mechanisms and underlying causes as accidents, so studying near-misses would give valuable information for the redesign of socio-technical systems (Hollnagel 2009).

Observing successes, near-misses and incidents comes at an increased cost regarding data collection and data analysis; however, there are also a number of advantages. First, focusing on near-misses reveals how the socio-technical system works on the functional and operational boundaries of the system. Systems operating on the functional and operational boundaries will show performance variability not seen in routine operation (Øvergård et al. 2015a; Bjørkli et al. 2007; Øvergård et al. 2010). Observing near-misses also gives us the ability to identify how humans and automatons react to avoid accidents during critical situations. This has seldom been observed and reported in academic literature, but there are a few exceptions (Mazaheri et al. 2018; Øvergård et al. 2015a).

Second, it is estimated that there are 600 times more near-misses than there are accidents (Rothblum et al. 2002). Hence, an approach that investigates the actual occurrence of navigational behaviour (whether it is categorised as routine work, nearmisses, incidents or accidents) will have more data to work with than both the traditional accident investigation approach and the routine work approach.

Third, causal or statistical claims of human involvement in accidents based upon data from accidents (e.g. 'between 70-96\% of all accidents in the shipping industry are rooted in human error', Dhillon 2007, pp. 91-92) are affected by selection bias (Øvergård 2015), as the observation of human errors is dependent upon the occurrence of accidents. Also, there is a lack of data on non-accidents (or successful events), thus making it very challenging (if not impossible) to estimate the impact of human error on maritime accidents (Øvergård 2015).

An approach that collects all behavioural data from a system - both on successes or routine work, on near-misses or incidents and on accidents - will acquire data that may be used to estimate the contribution of a variable (e.g. human error) to the overall system safety (Øvergård 2015).

\section{Background for the research project}

The aim of this paper is to investigate the risk posed by crossing situations between a small manned passenger ferry named 'Ole III' and pleasure craft. The data collection 
was done as part of a larger project aimed at designing and implementing an unmanned autonomous passenger ferry (UAS) in the Husøysund strait in Tønsberg, Norway. Due to the novelty of using UAS for passenger traffic, there was a need to investigate the traffic situations that a future UAS might encounter in the Husøysund strait. Because Ole III navigates the same route that would be used by an UAS, the traffic situations that OLE III experienced would be indicative of the traffic situations that a UAS might encounter. Participatory observations were used to document all crossing situations that 'Ole III' was involved in at the Husøysund strait between 10 AM and 8 PM on all days between 4 June and 4 August 2018.

\section{The Husøysund strait}

Husøysund is a strait in the municipality of Tønsberg between the mainland (Husvik) and the island of Husøy. Husøysund is the main east-west sailable route out from the city of Tønsberg. The strait is between 100 and $150 \mathrm{~m}$ across, from shore-to-shore, and has a central channel more than $6 \mathrm{~m}$ deep with no traffic separation zones. The sailable channel through the strait is marked with red/green buoys, leaving a sailable channel between 40 and $60 \mathrm{~m}$ wide. The ferry route crosses the Husøysund strait between the coordinates $59.243248^{\circ} \mathrm{N} 10.460731^{\circ} \mathrm{E}$ and $59.243954^{\circ} \mathrm{N} 10.461588^{\circ} \mathrm{E}$, a distance of approximately $100 \mathrm{~m}$.

Husøysund is trafficked by many pleasure boats during the summer season. The strait is also navigated by a small number of commercial ships going to and from the Tønsberg harbour. Due to the layout of the strait and the weather conditions (wind and tidal currents), the operation of Ole III can be compared to that of small river-crossing passenger ferries.

\section{Characteristics and manning of Ole III}

Ole III operates as a manned and human-controlled passenger ferry with a maximum capacity of 11 passengers. It is $7.59 \mathrm{~m}$ long and $2.6 \mathrm{~m}$ wide. It has a $38 \mathrm{hp} \mathrm{Yanmar}$ engine with one propeller for propulsion. The ferry is operated by a single person with a captain's licence. The captain is responsible for the passengers and the equipment on board and conducts the transit using optical navigation. The only tools for navigation are binoculars and a magnetic compass. The captain does all the assessment of traffic and takes all decisions regarding handling of crossing situations and navigation according to experience and good judgement. Figure 1 shows a picture of Ole III. A crossing with Ole III takes about 2 min when traffic is low and weather conditions are good.

\section{Colregs and the traffic situation in Husøysund}

Crossing of Husøysund is particularly challengingly seen from a perspective of the International Regulations for Preventing Collisions at Sea (COLREGS) by the International Maritime Organisation (IMO 1972). Standard actions for vessels on a crossing 


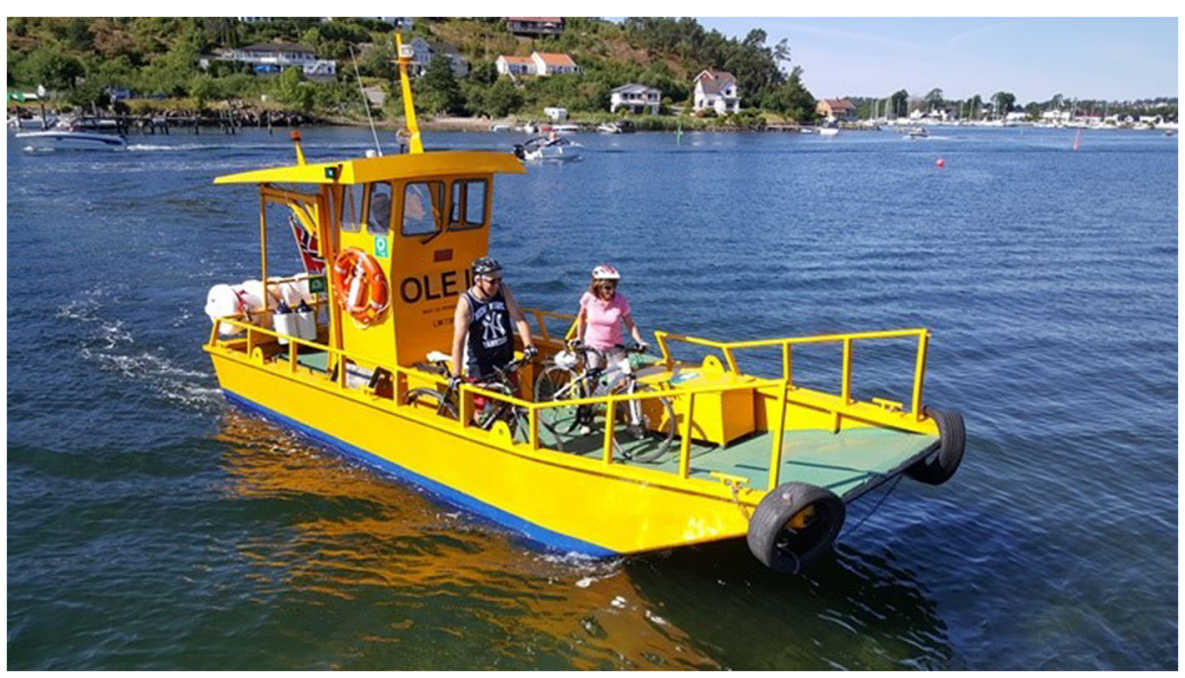

Fig. 1 The Ole III passenger ferry (photo by Tønsberg Sjømannsforening, used with permission)

course are determined by Rule 15 in COLREGS stating that any vessel that is on a crossing course with another vessel which is on its starboard side shall give way to the other vessels, and if possible avoid changing course. This means simply that the 'giveway vessel' must make a course change to starboard to cross aft of the vessel that has the right of way (the stand-on-vessel). Rule 17a (i) states that the stand-on-vessel shall keep its course and speed constant during the crossing phase, but Rule 17a (ii) also states that the stand-on-vessel must be ready to make an evasive manoeuvre if the give-way-vessel does not perform the requisite manoeuvres as determined in Rule 15 (IMO 1972).

A complicating element in the present case is Rule 44 of 'Sjøveisreglene' ('Seafaring rules' Norwegian translations of COLREGS as well as a special set of rules for Norwegian waters) (Department of Fisheries and Commerce 1975). Rule 44 states that all pleasure craft shall, as far as possible, keep away from larger vessels, vessels transporting according to a schedule or other commercial vessels when they pass a narrow passage, a heavily trafficked fairway or a port. Ole III is such a commercial vessel that sails passengers, and Husøysund is a narrow passage with heavy traffic. Hence, pleasure craft should keep away from Ole III while it crosses Husøysund. However, since Ole III does not have manoeuvring problems or a large draft, Ole III cannot with juridical certainty claim to have the right-of-way against vessels that are on its starboard side. Note also that the law states '... as far as possible keep away from...', which is something different than 'giving way'. Thus, the juridical status of whether Ole III has the right-of-way against all other vessels in Husøysund is not clear. Problems might arise if the captain on Ole III acts according to Rule 44, which goes counter to Rule 15 in COLREGS (IMO 1972) with regard to ships on the starboard side of Ole III because the success of this strategy is dependent on pleasure craft skipper and Ole III's captain having the same understanding of Ole III's status.

From a psychological perspective, such a plan can only be successful if both have the same mental models of how crossing situations should be resolved. Shared mental models are important for collaboration and for teamwork (Stout et al. 1999; Mathieu 
et al. 2000), and sharing of information and/or communication is central to ensure a shared understanding of situations (Stanton et al. 2006; Nazir et al. 2015) as well as to the safety of navigation (Øvergård et al. 2015b). Our study is aimed at identifying how the skippers of the pleasure craft and the captain of Ole III resolve crossing situations.

\section{Challenges with pleasure craft}

Most of the vessels passing through Husøysund are pleasure craft. A report from the Norwegian Maritime Authority (2012) indicates that the major challenges with pleasure craft in Norwegian waters that can be precursors to accidents are (1) the lack of competency in proper navigation and behaviour at sea, (2) the use of intoxicantsparticularly alcohol — and (3) high speeds - in recent years, the number of pleasure craft capable of high speeds has increased in Norway.

The lack of competence for pleasure craft skippers is underscored by the Norwegian Maritime Authorities' campaign to increase awareness of proper behaviour at sea through the 'Løft blikket' (eng. raise your eyes) campaign (Norwegian Maritime Authority 2019). The lack of navigational skills for owners of pleasure craft can partly be attributed to lack of training. In Norway, there were no requirements of proficiency, skill or need of training for skippers of pleasure craft shorter than $15 \mathrm{~m}$ until 2010. In 2010, the boat licence test was made mandatory for all persons born on 1 January 1980 or later. People born before that date are still not required to have a boat licence to sail a pleasure craft with an overall length shorter than $15 \mathrm{~m}$. In a recent study (Amundsen and Bjørnskau 2017), about $45 \%$ of pleasure craft owners in Norway $(N=11,122)$ reported that they had the boat licence, while $16.5 \%$ of the sample had other certificates or other types of training. This leaves about $38.5 \%$ of Norwegian pleasure craft skippers that are without any proof of competence in navigation.

Intoxication is also a challenge, as people's willingness to drink while sailing is much higher than their willingness to drink and drive (Norwegian Maritime Authority 2012). The permitted alcohol limit in Norway while sailing private pleasure craft less than $15 \mathrm{~m}$ in length is $0.08 \%$ (Department of Commerce and Fisheries 1998). A recent report from the Institute of Transport Economics reports that in a Norwegian sample, about $45 \%$ of all users of pleasure craft in Norway reported drinking alcohol just before or during a boat trip (Amundsen and Bjørnskau 2017, p. IV). Also, a recent report from the Accident Investigation Board Norway (AIBN 2019b, p. 59) has found that for all pleasure boat accidents where someone died, intoxication was involved in $28 \%$ of all types of accidents and in $53 \%$ of all collisions/groundings.

Similarly, the number of pleasure craft capable of high speeds has increased in Norway (Norwegian Maritime Authority 2012). High speed was found to be present in $5 \%$ of all accidents and in $37 \%$ of all collisions and groundings with pleasure craft. In a sample consisting of 10,788 owners of pleasure craft in Norway, about $56 \%$ of them reported to have sailed faster than the allowed speed close to shore, and about $5 \%$ say they often sail faster than the speed limit when they are close to land. The willingness to sail at high speeds is exacerbated by the lack of competencies as well as when the skipper is intoxicated (ibid).

Hence, we can expect to routinely see non-compliance of COLREGS from pleasure craft in the Husøysund strait. One of the main challenges is that we can expect that a 
strict adherence to COLREGS by Ole III (i.e. expecting other vessels to give way and pass aft of Ole III) may actually lead to collisions or incidents because other pleasure craft do not necessarily adhere to COLREGS. Hence, this requires us to investigate routine situations, deviations from COLREGs, near-misses and accidents and to see how an experienced captain would resolve these situations (Øvergård et al. 2018).

\section{Research questions}

The challenges described above, combined with the fact that the ferry at Husøysund is to be replaced by a small autonomous unmanned passenger ferry, lead to the following research questions: 'What is the prevalence of deviations from COLREGS during crossing situations involving pleasure craft?' and 'What are the associated risks of these incidents related to the safety of Ole III and its passengers?'

The data gathered and the resulting analysis will give an empirical view of the expected occurrence of non-regulatory behaviours from the other pleasure craft, and it will also identify the actions taken by the captain aboard Ole III to resolve such situations. Knowledge of the prevalence and risk of these challenges is critical for identifying the risks related to the operation of unmanned autonomous passenger ferries and to exemplify the challenges we need to take into consideration when designing autonomous passenger ferries.

\section{Methods}

\subsection{Data collection}

Data was collected through participative observation between 10:00 and 20:00 each day from 4 June to 4 August 2018. Two second-year nautical students from the Department of Maritime Operations, University of South-Eastern Norway, took turns to participate on all crossings with Ole III in the stated period. Data was collected using a pre-made questionnaire, and for each crossing, the students recorded the following variables: (1) date and time, (2) the number and type of crossing vessels on starboard and on the port side, (3) number of passengers (adults, children and passenger with a need for assistance) and bicycles and (4) notations of all instances where COLREGS are not followed, with a brief description of the incident and what the captain of Ole III did to handle the situation. The data was entered into an Excel sheet, and categories of actions and types of situations were established through thematic analysis (Braun and Clarke 2006). The numerical data were analysed using IBM SPSS 26.

\section{Results}

\subsection{Observations}

Data from 4802 crossings in Husøysund were recorded. During these 4802 crossings, there were no accidents involving collision, allisions or groundings. In 1650 of these 
crossings, there were no other vessels present, while on 3152 crossings, other vessels were on a crossing course with Ole III. Of the 3152 crossings with other vessels present, a total of 7415 vessels were recorded to have a crossing course with Ole III where 4150 vessels coming at starboard and 3265 vessels at the port side of Ole III. Ole III transported 6225 passengers of which 1227 were under 16 years of age and 60 needed assistance to get on board (mostly kids in kindergarten). In addition, a total of 3995 bikes were transported across Husøysund.

\subsection{Incidents}

Altogether, 279 incidents with other vessels on a conflicting course were given a risk classification. This amounts to $5.8 \%$ of the total number of Ole III's crossings and $8.9 \%$ of the total number of crossings with other vessels present.

These incidents involved non-regulatory behaviours breaching COLREGS or involved other incidents (excessive speed, dangerous navigation) that could have impacted the safety of the ferry and its passengers. Each written description of the events was analysed with a thematic analysis (Braun and Clarke 2006) and assessed for risk by two persons, a navigator with 8 years of sailing onboard vessels in the Royal Norwegian Navy and 20 years of experience in different jobs in the maritime industry and a Professor of maritime human factors. The categories were defined according to (1) the actions of Ole III's captain, (2) the notes made by the observer in the questionnaire, (3) an assessment of the risk potential by the two assessors.

The first risk category 'deviation' was defined as a deviation from the COLREGS where Ole III waited for the other vessels to pass or passed at the aft of the other vessels even though Ole III had the right of way. In this category, there was no imminent danger to Ole III or its passengers. This risk category occurred 229 times $(4.8 \%$ of the total, $7.3 \%$ of crossings with other vessels present).

The second risk category 'dangerous' was defined by situations where the captain of Ole III had to reduce forward thrust (i.e. reduce speed) and/or change course to avoid conflict with other vessels. We also included other vessels passing Ole III at high speeds (well above the 5-knot speed limit in the Husøysund strait) where the observer also has noted specifically that the other vessels was sailing at high speed. 'Dangerous incidents' occurred a total of 39 times $(0.8 \%$ of the total number of Ole III's crossings, and $1.2 \%$ of Ole III's crossings with other vessels present).

The final risk category 'critical' was reserved for incidents where Ole III had to reverse thrust and/or do an evasive manoeuvre and/or use the horn to give a signal to avoid an incident. This represented the incidents with the highest risk of collision in the observed data set. This category occurred 12 times $(0.2 \%$ of the total; $0.38 \%$ of crossings with other vessels).

Unfortunately, we cannot say whether the number of deviations is 'large' as we do not have any data from other comparable maritime sources. However, our experience from navigation with pleasure craft in Norway tells us that our observations are not abnormal for the Norwegian summer period. This experience is also supported by the recent review of reported pleasure craft accidents between 2003 and 2017 by AIBN (2019a, b). 


\subsection{Incidents and the number of other vessels present}

A binary logistic regression on the 3152 crossings where other vessels were present indicated that the number of vessels present on a crossing course was clearly associated with the occurrence of incidents $(\operatorname{Exp}(\mathrm{B})=1.154,95 \% \mathrm{CI}[1.09,1.23], p<0.0001)$, i.e. a larger number of vessels increased the risk of incidents. We also found that the number of vessels coming towards Ole III's port side increased the risk of an incident $(\operatorname{Exp}(\mathrm{B})=1.31,95 \%$ CI $[1.21,1.43], p<0.001)$, while this was not the case for the number of vessels coming towards Ole III's starboard side $(\operatorname{Exp}(B)=1.01,95 \%$ CI $[0.92,1.11], p=.829)$.

\subsection{Risk relating to which side the vessels come from}

As discussed in the introduction, it is of interest to see how the incidents are distributed according to which side the involved vessels come from (relative to Ole III). The distribution of events as a function of risk category and which side the vessels came from is described in Table 1. There were no other vessels on a crossing course to Ole III on $1650(34.4 \%)$ of all passages of Husøysund. There were fewer passages where Ole III had vessels on a crossing course only on the port side (840 events, $17.5 \%)$, as compared with those on the starboard side $(1137,23.7 \%)$ or both sides $(1175,24.5 \%)$. In all these events with other vessels present, we have determined where the offending vessel came from (note: offending here means that this was the vessel that created the situation, either by recklessness, lack of attention or a failure to understand and/or follow the anti-collision regulations).

For a total of 30 incidents, information was lacking about which side the offending vessel came from. The questionnaire did not ask for explicit information about which side the offending vessel came from, so while the descriptions of these 30 incidents registered that there were vessels on a crossing course coming from both sides of Ole III, they did not specify which side.

When we assess the crossing situations where other vessels approach only on starboard or only on the port side of Ole III, we see that $5 \%$ of crossings with other vessels approaching Ole III's starboard side had an incident (1137 crossings and 57

Table 1 Risk categorisation and direction other vessels

\begin{tabular}{|c|c|c|c|c|c|}
\hline \multirow[t]{2}{*}{ Risk category } & \multicolumn{4}{|c|}{ Side the other vessels came from* } & \multirow[t]{2}{*}{ Sum } \\
\hline & None & Stb only & Port only & Both sides & \\
\hline Normal situation & 1650 & 1080 & 757 & 1036 & 4523 \\
\hline Deviation & - & 44 & 71 & 113 & 228 \\
\hline Dangerous & - & 12 & 7 & 20 & 39 \\
\hline Critical & - & 1 & 5 & 6 & 12 \\
\hline Sum & 1650 & 1137 & 840 & 1175 & 4802 \\
\hline
\end{tabular}

Cross table of risk categorisation of events and the side other vessels came from

* Numbers for the risk categories 'Deviation', 'Dangerous' and 'Critical' indicate the number of times the offending vessel came from starboard, port or both sides. None, no other vessels present; Stb, starboard 
incidents) while $9.9 \%$ of crossings with other vessels approaching on Ole III's port side had incidents ( 840 crossings and 83 incidents). This means that situations with pleasure craft approaching Ole III's port side had twice as high relative risk (RR) of an incident compared with situations with pleasure craft approaching Ole III's starboard side $(\mathrm{RR}=1.97,95 \% \mathrm{CI}[1.42,2.73], p<0.0001)$. We calculated $\mathrm{RR}$ according to the method described by Altman (1991). That the risk for experiencing incidents is larger with vessels coming from the port side of Ole III may indicate that skippers of pleasure craft have a lax attitude or knowledge of basic navigational rules such as Rule 15 in COLREGS (IMO 1972).

\subsection{Causes of incidents}

Thematic analysis (Braun and Clarke 2006) of the descriptions of the incidents found the following themes: 'did not give way', 'high speed', 'lack of attention', 'on wrong side of fairway', 'other' and 'high traffic density'. Table 2 shows the cross table of the categorisation of risk and the risk assessment for all incidents. As we can see from Table 2, the categories of 'did not give way' occurs 27 and 40 times more often than 'lack of attention' and 'too high speed', respectively. Also, the situations 'other vessels did not give way', 'other vessels had too high speed' and 'other vessels showed lack of attention' were involved in all 'critical' and all but one of the 'dangerous' incidents.

The category 'high traffic density' had an average of 5.24 other vessels (95\% CI $[4.01,6.46])$ on a crossing course with Ole III, which was markedly higher than the other situations (all differences were significant at $p<.0001$ ) except for the 'other vessels on the wrong side of fairway' which included only two observations.

\subsection{Handling of crossing situations}

Table 3 shows the relationship between the type of navigation situations and the control strategies used by Ole III's captain irrespective of the risk categorisation of the incidents.

As can be seen in Table 3, the majority of incidents where the other vessels did not follow COLREGS were met with an action that avoided the further escalation of an incident.

Table 2 Cross table of OV actions and risk category

\begin{tabular}{|c|c|c|c|c|c|}
\hline Risk category & No. vessels & Deviation & Dangerous & Critical & Total \\
\hline OV did not give way & 2.66 & 205 & 30 & 9 & 244 \\
\hline OV had too high speed & 1.50 & - & 5 & 1 & 6 \\
\hline OV lack of attention & 2.11 & 4 & 3 & 2 & 9 \\
\hline $\mathrm{OV}$ on wrong side of fairway & 4.00 & 1 & 1 & - & 2 \\
\hline Other & 2.40 & 3 & - & - & 3 \\
\hline High traffic density & 5.24 & 15 & - & - & 15 \\
\hline Total & & 228 & 39 & 12 & 279 \\
\hline
\end{tabular}

$O V$, other vessels; No. vessels, average number of vessels on a conflicting course with Ole III for each situation 


\subsection{Crossing situations, control strategies and risk categories}

We can divide the actions of Ole III into two categories - 'active' and 'passive' control strategies (Bjørkli et al. 2007; Øvergård et al. 2010). 'Active' strategies involve actions which assert the intentions of the captain of Ole III. Examples of active strategies in our data are maintaining steady heading and speed (despite the presence of other vessels on a crossing course) and communicating in some way with the other vessels to make one's intentions clear (e.g. using hand signs or the horn of the Ole III). With 'passive' control strategies, we mean an action that reduces the risk of the situation by avoiding the other vessels. These 'passive' control strategies involved waiting before entering the fairway, sailing aft of the other vessels, reducing speed or the active reversion of thrust aft or emergency deviation to avoid collision.

To see whether there is a relationship between active and passive control strategies, we have calculated the cross tables that contain information about the other vessels' actions and the control strategies of Ole III's captain for each of the three risk categories 'deviation' (see Table 4), 'dangerous' (see Table 5) and 'critical' (see Table 6).

As we can see from Table 4, in the majority of navigational situations deviating from COLREGS, the captain of Ole III used a passive control strategy (waiting, sailing aft of the other vessels, or reducing speed or deviating) a total of 204 times (89.5\% of incidents categorised as 'deviation'). Active assertive strategies by keeping heading and speed or communicating were used 24 times (10.5\% of incidents).

For incidents categorised as 'dangerous', the captain of Ole III used a passive control strategy (by waiting, sailing aft of the other vessels, and reducing speed or deviating) at a total of 31 times (79\% of incidents categorised as 'dangerous'), while active assertive strategies by keeping heading and speed were used 8 times $(21 \%)$.

For the 'critical' incidents, Ole III used a passive control strategy (by sailing aft of the other vessels and reducing speed or deviating) a total of 8 times $(67 \%)$, while active

Table 3 Control strategies of Ole III's captain for all risk categories

\begin{tabular}{|c|c|c|c|c|c|c|c|}
\hline \multirow[t]{2}{*}{ Situation } & \multicolumn{6}{|c|}{ Control strategies of the captain of Ole III } & \multirow[b]{2}{*}{ Total } \\
\hline & $\begin{array}{l}\text { Kept course } \\
\text { and speed }\end{array}$ & Waited & $\begin{array}{l}\text { Sailed aft } \\
\text { of OV }\end{array}$ & $\begin{array}{l}\text { Reduced speed } \\
\text { or deviated }\end{array}$ & Com. & Used horn & \\
\hline No other vessels present & 1650 & - & - & - & - & - & 1650 \\
\hline Normal navigation & 2867 & - & - & - & - & - & 2876 \\
\hline OV did not give way & 15 & 106 & 52 & 58 & 6 & 9 & 246 \\
\hline OV had too high speed & 3 & 2 & 1 & - & - & - & 6 \\
\hline OV lacked attention & 1 & 2 & 3 & 1 & - & 2 & 9 \\
\hline OV on wrong side of fairway & 1 & - & - & 1 & - & - & 2 \\
\hline Other & - & 5 & - & - & - & - & 5 \\
\hline High traffic density & - & 15 & 2 & - & - & - & 17 \\
\hline Total & 4537 & 130 & 58 & 60 & 6 & 11 & 4802 \\
\hline
\end{tabular}

$O V$, other vessels; Com., 'communicating'; The 'other' situation category involves situations like kayak in the strait, pleasure craft fishing in the strait and even 'Viking ship with reduced manoeuvrability from port' (Tønsberg is the home of a number of Viking ship replicas) 
Table 4 actions of OV and Ole III's control strategies for risk category 'deviation'

\begin{tabular}{|c|c|c|c|c|c|c|c|}
\hline \multirow[t]{2}{*}{ Situation } & \multicolumn{6}{|c|}{ Control strategies of the captain of Ole III } & \multirow[b]{2}{*}{ Total } \\
\hline & $\begin{array}{l}\text { Kept course } \\
\text { and speed }\end{array}$ & Waited & $\begin{array}{l}\text { Sailed aft } \\
\text { of OV }\end{array}$ & $\begin{array}{l}\text { Reduced speed } \\
\text { or deviated }\end{array}$ & Com. & $\begin{array}{l}\text { Used } \\
\text { horn }\end{array}$ & \\
\hline OV did not give way & 15 & 103 & 48 & 32 & 5 & 2 & 205 \\
\hline OV had too high speed & - & - & - & - & - & - & - \\
\hline OV lacked attention & 1 & 2 & 1 & - & - & - & 4 \\
\hline $\mathrm{OV}$ on wrong side of fairway & 1 & - & - & - & - & - & 1 \\
\hline Other & - & 3 & - & - & - & - & 3 \\
\hline High traffic density & - & 14 & 1 & - & - & - & 15 \\
\hline Total & 17 & 122 & 50 & 32 & 5 & 2 & 228 \\
\hline
\end{tabular}

$O V$, other vessels; Com., 'communicating'; the 'other' situation category involves situations like kayak in the strait, pleasure craft fishing in the strait and even 'Viking ship with reduced manoeuvrability from port' (Tønsberg is the home of a number of Viking ship replicas)

control strategies were used 4 times (33\%). We aggregated results (see Table 7) for passive and active control strategies from Tables 4, 5, and 6 to see whether there was a relationship between the risk category of incidents and the control strategy of Ole III.

As we can see, the active control strategies are underrepresented for the 'deviation' risk category, but overrepresented in the 'dangerous' and 'critical' risk categories. A chi-square test of the numbers in Table 7 indicates that there is an association between control strategy mode (active/passive) and the risk category of the incidents ( $X^{2}=7.613$, $d f=2, p=.022$ ). Active control strategies become more prevalent in the higher risk categories; for example, active control strategies have an almost twice as high relative risk of an incident in the dangerous category compared with the deviation category $(\mathrm{RR}=1.90,95 \% \mathrm{CI}[0.96,3.76], p=.067)$, while the critical category had more than threefold higher relative risk of an incident compared with the deviation category $(\mathrm{RR}=3.79,95 \% \mathrm{CI}[1.22,11.76], p=.021)$. The sample size was not sufficient for

Table 5 actions of OV and Ole III's control strategies for risk category 'dangerous'

\begin{tabular}{|c|c|c|c|c|c|c|c|}
\hline \multirow[t]{2}{*}{ Situation } & \multicolumn{6}{|c|}{ Control strategies of the captain of Ole III } & \multirow[b]{2}{*}{ Tota } \\
\hline & $\begin{array}{l}\text { Kept course } \\
\text { and speed }\end{array}$ & Waited & $\begin{array}{l}\text { Sailed aft } \\
\text { of OV }\end{array}$ & $\begin{array}{l}\text { Reduced speed } \\
\text { or deviated }\end{array}$ & Com. & Used horn & \\
\hline OV did not give way & - & 3 & 2 & 21 & - & 4 & 30 \\
\hline OV had too high speed & 3 & 2 & - & - & - & - & 5 \\
\hline OV lacked attention & - & - & 2 & - & - & 1 & 3 \\
\hline OV on wrong side of fairway & - & - & - & - & - & 1 & 1 \\
\hline Other & - & - & - & - & - & - & - \\
\hline High Traffic Density & - & - & - & - & - & - & - \\
\hline Total & 3 & 5 & 4 & 22 & - & 5 & 39 \\
\hline
\end{tabular}

$O V$, other vessels; Com., 'communicating' 
Table 6 actions of OV and Ole III's control strategies for risk category 'critical'

\begin{tabular}{llllllll}
\hline Situation & \multicolumn{2}{l}{ Control strategies of the captain of Ole III } & & \\
\cline { 2 - 6 } & $\begin{array}{l}\text { Kept course } \\
\text { and speed }\end{array}$ & & Waited & $\begin{array}{l}\text { Sailed aft } \\
\text { of OV }\end{array}$ & $\begin{array}{l}\text { Reduced speed } \\
\text { or deviated }\end{array}$ & $\begin{array}{l}\text { Com. } \\
\text { horn }\end{array}$ & $\begin{array}{l}\text { Total } \\
\text { horn }\end{array}$ \\
\hline OV did not give way & - & - & 1 & 5 & - & 3 & 9 \\
OV had too high speed & - & - & 1 & - & - & - & 1 \\
OV lacked attention & - & - & - & 1 & - & 1 & 2 \\
OV on wrong side of fairway & - & - & - & - & - & - & - \\
Other & - & - & - & - & - & - & - \\
High traffic density & - & - & 1 & - & - & - & - \\
Total & - & - & 2 & 6 & - & 4 \\
\hline
\end{tabular}

$O V$, other vessels; Com., 'communicating'

the dangerous and the critical categories to obtain a stable point estimate of the RR of an incident, although the estimated risk was higher for the critical category $(\mathrm{RR}=1.63$, $95 \%$ CI $[0.59,4.47], p=.347)$.

\section{Discussion}

This paper sets out to identify instances of non-compliance with the rules of navigation from other vessels (mostly pleasure craft) in relation to the operation of the small passenger vessel Ole III in the Husøysund strait in Tønsberg municipality, Norway. We found that non-compliance to COLREGS occurred a total of 279 times (ca. 8.8\% of all crossings with other vessels on a crossing course). The most common incidents were when other vessels did not give way when they should have (244 times, $87 \%$ of all incidents), and there were a few instances of reckless sailing (6 times, 2\%), and nine instances $(3 \%)$ where the skipper of the other pleasure vessels was not paying attention, was not present at the wheel and/or was occupied with other tasks.

The main outcome of these results is that for this area and time of year we must expect that other pleasure craft will routinely deviate from COLREGS during crossing situations with a small passenger ferry. We also found that the captain of Ole III's

Table 7 Relationship between control strategies and risk categories

\begin{tabular}{lllll}
\hline Control strategy & \multicolumn{2}{l}{ Risk category } & & Total \\
\cline { 2 - 4 } & Deviation & Dangerous & Critical & \\
\hline Passive & $204(90 \%)$ & $31(79 \%)$ & $8(67 \%)$ & $243(87 \%)$ \\
Active & $24(10 \%)$ & $8(21 \%)$ & $4(33 \%)$ & $36(13 \%)$ \\
Total & 228 & 39 & 12 & 279 \\
\hline
\end{tabular}

Cells contain the number of times a control strategy intersected with one of the three risk levels. Percentages indicate the number of times a control strategy has been used for a given risk level 
control strategy of the small passenger ferry was related to the seriousness of the incidents - with active control strategies (keeping heading and speed, communicating or using the sound horn) being more prevalent in higher risk situations. Passive control strategies (waiting to allow the other vessels to pass, sailing aft of the other vessels (even though you have the right of way)) were associated with lower levels of risk categories and tended to keep Ole III out of harm's way on several occasions.

Interestingly, the interpretation of the results is dependent upon which side the vessels came from. The 165 incidents with vessels that had Ole III on their starboard side (i.e. the approach towards Ole III's port side) are classical cases of pleasure craft owners who are clearly in breach of the anti-collision regulations. This can be either because of lack of training/understanding of the basics of navigation, lack of attention or a result of inebriation or recklessness. As such, these 165 incidents are examples of how a skilled captain contributes to navigational safety by taking actions that defuse other people's erroneous actions. According to this perspective, these incidents are instances of how skilled humans are responsible for ensuring safety of navigation (Bjørkli et al. 2007), and hence present a counter-weight to the (some would say erroneous) view that most accidents are attributed to human error (see, e.g. Dhillon 2007).

The incidents involving vessels on Ole III's starboard side are a bit more complicated to discuss, as Ole III has a status as a commercial vessel and according to Rule 44 in the national navigation regulations (Department of Fisheries and Commerce 1975) other vessels should if possible keep away from Ole III. Our discussions with Ole III's captains gave indications that they interpreted Rule 44 to say that Ole III had the right of way also against pleasure craft that came on Ole III's starboard side. However, through discussions with experts in maritime law, we have understood that it is not clear whether Ole III would be deemed responsible or not if there was a collision between Ole III and another vessel coming at Ole III's starboard side. This is partly because Ole III does not have problems with navigation in the narrow strait and that they therefore can be expected to change course if situations would arise that could lead to a collision.

From a pragmatic viewpoint, it is of less importance why the captains of the two vessels act like they do-whether it is out of ignorance of the rules, carelessness, lack of attention, intoxication or other reasons. In the end, it is the practical navigational situations that have to be resolved. One way of resolving this is to take a descriptive approach, such as focusing on whether people follow rules; however, this will only help in attributing blame, or judicial responsibilities, and will not help in explaining actual behaviour (i.e. why people choose to follow a rule or not). Table 8 describes a decision situation involving four different outcomes for crossing situations with vessels on Ole III's starboard side. On the vertical side in the decision matrix, we have the decision of the captain of Ole III who either acts like Ole III has the right of way or does not (yes/ no), and on the horizontal side, we have the decision of the skipper of the other vessels who either thinks that Ole III has the right of way or not (yes/no).

These four possible outcomes are results of whether the two adaptive agents intended to act according to Rule 44 (e.g. Ole III has right-of-way) or not. The main aspect is whether the intentions of the two vessels correspond. As such, it describes sets of situations that result in match or mismatch between adaptive agents (e.g. those in control of the vessels). The concept of 'adaptive agents' includes both humans and 
Table 8 Possible outcomes and risks of different mental models

Does the skipper of a vessel on starboard side of Ole III understand Ole III's intentions?

Yes No

Does the captain of Ole III Yes Normal situation: Ole III will keep act like he has the right-of-way according to Rule 44 ? course and speed, other vessels will slow down to avoid crossing ahead of Ole 3.

\section{No Efficiency Incident: Mismatch between mental models. Ole III will change course to pass aft of other vessels. Other vessels will slow down to give Ole III the right of way. Main problem is lack of efficiency.}

Safety Incident: Mismatch between mental models. Both Ole III and the other vessels intend to stand on course. One of the vessels must make an avoidance manoeuvre. Main challenge is safety.

Normal situation: Ole III will change course and pass aft of the other vessels. Other vessels will keep course and speed.

Error types involving humans and/or technical systems (see, e.g. Reason 1990, 1997) will come in addition to the problematic scenarios relating to (mis)-match of agents' intentions which are described here

autonomous technical systems. Thus, the situations described below will also be relevant for the interactions and cooperation between humans vs. humans, humans vs. automatons and automatons vs. automatons. Irrespective of the nature of the adaptive agent, the challenges described in Table 8 are not possible to resolve unless (1) it is possible to establish communication of intention between vessels or (2) it is possible to ensure that all agents follow the COLREGS at all times. The last request is highly unlikely to ever happen as long as pleasure craft skippers lack elementary navigational competencies and knowledge of COLREGS.

\subsection{Suggested control strategies}

We have seen that the prospect of a close rule-following approach-like the one in use for active control strategies (keeping heading and speed, communicating or using horn) - is associated with a higher risk of incidents during crossing situations. Active control strategies are associated with higher risk categorisation, partly due to the fact that an assertive control strategy will allow other vessels to come closer, thus reducing safety margins. Hence, using only active control strategies is not advisable as long as one cannot ascertain that the other vessels understand your intentions and that they are willing or able to deviate in accordance with COLREGS.

Passive control strategies ensure that Ole III avoids risky crossing situations. As our data show, passive control strategy reduced the risk levels of crossing situations. In this regard, it might be worthwhile for small passenger ferries to 'play it safe', that is, use passive control strategies that avoid conflict situations at all costs (see, e.g. Alves and Cruz 2016). One possible solution would be to say that Ole III (or any other small passenger vessels) has to give way to all other vessels on its starboard side (in accordance with Rule 15 in COLREGS). In this case, Ole III would always act 
according to a passive control strategy. This could partly remove the problem of a conflict of intentions (see Table 8) as the number of close-quarter crossings would be reduced, and thus, the challenge stemming from a conflict of intentions would be reduced. However, such an approach would come at the cost of efficiency when there is heavy crossing traffic in the Husøysund strait.

Now, a third possibility would be to establish formalised ways to communicate intentions between vessels - including pleasure craft (see Porathe 2015). There have recently been research projects focusing on the improvement of navigational safety through the sharing of route plans between commercial vessels such as MONALISA 2.0 (Sjofartsverket.se n.d.) and the Sea Traffic Management Validation Project (STM n.d.). These projects focus (among other things) on sharing of route plans. Although these projects present possible improvements to maritime safety, they are of less help for the commercial vessels that interact with pleasure craft. First, route plans are not mandatory for pleasure craft. Second, the projects focus on advanced equipment such as the Automated Identification System (AIS) which is standard equipment on commercial vessels but is not required and is too expensive for most normal pleasure craft. Hence, there is a need for other methods for communicating intentions of commercial vessels which will navigate among pleasure craft (Porathe 2015).

\subsection{Limitations}

The main limitation of this paper is that we have only collected data on one place or region and in a fixed time span. Because we lack comparable data from other regions (indeed from any region), we cannot say whether our data are representative of a population of pleasure craft skippers or not. However, the lack of comparable data does not reduce the validity of our results; it just makes generalisation much more challenging. However, we can say that our findings regarding the number of pleasure craft which ignore basic navigational rules are in line with what has been described in other national reports (e.g. Norwegian Maritime Authority 2012). Now, we still need data from other parts of the world to say anything about the extent of national/cultural differences between the navigation of pleasure craft. However, our method described in this paper can be used in all parts of the world to gather information about the extent that pleasure craft pose a risk for small passenger ferries.

The present project did not gather data before 10 o'clock in the morning each day, thereby losing some information from the morning. This was a time of day that we later understood was quite busy as many pleasure boat owners sailed out early in the morning. Hence, we lost a number of possible observations. Despite this, we believe that the sample size is sufficient to describe and categorise the majority of navigational events and incidents that normally occur in Husøysund.

One challenge with our data is that we do not know whether (and if yes, when) the captains of Ole III thought they had the right-of-way. We know that they did not always act like they had the right of way as they waited and gave way for a number of vessels coming from the starboard side. This creates a challenge for our interpretation of the data relating to incidents with vessels coming in at Ole III's starboard side.

Differences in environmental conditions, such as poor weather, reduced sight distance and the presence of heavy winds, waves and currents, have not been discussed in the present paper. There are a number of reasons for this - first, the summer of 2018 
was exceptionally hot and dry with very few days of heavy rain and high winds which led to a large number of pleasure craft out in the Oslofjord area over the whole observational period - thereby increasing the number of observed crossing situations. Unfortunately, it did not allow us a real possibility to investigate the effects of weather on crossing situations and operation of the passenger ferry simply because there were almost no days with rain and/or winds. Also, in Norway, there is a tendency for pleasure craft skippers to go out to sea when the weather is good. In poor weather conditions, most pleasure craft are docked; hence, a number of interactions between pleasure craft and ferries are fewer than those during good weather conditions.

\section{Conclusion}

We observed deviations from COLREGS by pleasure craft in $279(8.8 \%)$ out of 3153 situations where other vessels were on a crossing course with Ole III. The majority of incidents observed were due to the lack of adherence to navigational rules by pleasure craft coming towards the port side of Ole III (i.e. the pleasure craft failed to follow the rule that you have to give way to vessels on a crossing course that is on your starboard side). This aspect needs to be addressed through the training of pleasure craft skippers, which in Norway unfortunately is not required for skippers born before 1 January 1980 (Department of Commerce and Fisheries 1998). We also found that active control strategies such as keeping heading and speed and communicating/using the horn were associated with higher risk situations.

Incidents involving events where vessels coming from the starboard side of Ole III are further complicated by the interpretation (or lack of knowledge) of Rule 44 in the national regulations (Department of Fisheries and Commerce 1975) which says that pleasure craft should keep away from commercial vessels travelling according to a schedule. In this case, events can be caused by the differing intentions of the skippers of the involved vessels (as described in Table 3). It is also possible that some of these incidents could actually be created by the captains of Ole III if they insist on following Rule 44 contrary to the other vessels' expectations. Our suggestion to solve this challenge for small vessels that interact with pleasure craft is twofold: first, to have small passenger ferries adopt largely passive control strategies - to the extent that they give way to vessels to their starboard side - and second, to create a way in which small passenger ferries can communicate its intentions to pleasure craft who do not have equipment such as radar, AIS or other advanced navigation systems. This is, as mentioned by Porathe (2015), a possible topic for future research.

\section{Acknowledgements Open Access funding provided by University Of South-Eastern Norway.}

Open Access This article is licensed under a Creative Commons Attribution 4.0 International License, which permits use, sharing, adaptation, distribution and reproduction in any medium or format, as long as you give appropriate credit to the original author(s) and the source, provide a link to the Creative Commons licence, and indicate if changes were made. The images or other third party material in this article are included in the article's Creative Commons licence, unless indicated otherwise in a credit line to the material. If material is not included in the article's Creative Commons licence and your intended use is not permitted by statutory regulation or exceeds the permitted use, you will need to obtain permission directly from the copyright holder. To view a copy of this licence, visit http://creativecommons.org/licenses/by/4.0/. 


\section{References}

AIBN (2019a) Mapping of recreational craft accidents. Main report. Report Marine 2019/02. Accident Investigation Board Norway, Lillestrøm https:/www.aibn.no/Marine/Published-reports/2019-02-eng (Accessed 30 Dec 2019)

AIBN (2019b) Mapping of recreational craft accidents. Part B. Mapping of historical accidents 2008-2017. Report Marine 2019/02. Accident Investigation Board Norway, Lillestrøm https://www.aibn. no/Marine/Published-reports/2019-02-eng (Accessed 30 Dec 2019)

Altman DG (1991) Practical statistics for medical research. Chapman and Hall, London

Alves JC, Cruz NA (2016) AIS-enabled collision avoidance strategies for autonomous sailboats. In: Friebe A, Haug F (eds) Robotic sailing 2015. Springer, Cham, pp 77-87

Amundsen AH, Bjørnskau T (2017) Bruk av fritidsbåt i Norge. Ulykkesinnblanding, sikkerhetsatferd og holdninger. TØI Report 1547/2017. Institute of Transport Economics, Oslo https://www.toi.no/getfile. php?mmfileid=45470 (Accessed 14 Jan 2020)

Bjørkli CA, Øvergård KI, Røed BK, Hoff T (2007) Control situations in high-speed craft operation. Cogn Tech Work 9(2):67-80

Braun V, Clarke V (2006) Using thematic analysis in psychology. Qual Res Psychol 3(2):77-101

Dekker S (2006) The field guide to understanding human error. Ashgate, Aldershot

Department of Commerce and Fisheries (1998) Law on leisure- and small boats (No. Lov om fritids- og småbåter (Småbåtloven) https://lovdata.no/dokument/NL/lov/1998-06-26-47 (Accessed 3 Mar 2020)

Department of Fisheries and Commerce (1975) Regulations for preventing collisions at sea (No. "Forskrift om forebygging av sammenstøt på sjøen (Sjøveisreglene)", https://lovdata.no/dokument/SF/forskrift/197512-01-5 (Accessed 3 Mar 2020)

Dhillon BS (2007) Human reliability and error in transportation systems. Springer Science \& Business Media

Hassel M, Asbjørnslett BE, Hole LP (2011) Underreporting of maritime accidents to vessel accident databases. Accid Anal Prev 43(6):2053-2063

Hollnagel E (2009) The ETTO principle: efficiency-thoroughness trade-off: why things that go right sometimes go wrong. CRC Press, Boca Raton

Hollnagel E (2013) A tale of two safeties. Nucl Saf Simul 4(1):1-9

Hollnagel E (2014) Is safety a subject for science? Saf Sci 67:21-24

Hollnagel E (2018) Safety-I and safety-II: the past and future of safety management. CRC Press, Boca Raton

IMO (1972) Convention on the International Regulations for Preventing Collision at Sea (COLREGs). International Maritime Organisation, London

Mathieu JE, Heffner TS, Goodwin GF, Salas E, Cannon-Bowers JA (2000) The influence of shared mental models on team process and performance. Appl Psychol 85(2):273-283

Mazaheri A, Montewka J, Nisula J, Kujala P (2018) Usability of accident and incident reports for evidencebased risk modeling-a case study on ship grounding reports. Saf Sci 76:202-214

Mohovic D, Baric M (2013) Contribution of the improvement of the safety of navigation of leisure crafts. Pomorstvo Sci J Marit Res 27(1):117-130

Nærings- og fiskeridepartementet (2020) Forskrift om fartøy under $24 \mathrm{~m}$ som fører 12 eller færre passasjerer [Regulations for vessels under 24 m carrying 12 or fewer passengers], FOR-2020-01-14-63, Nærings- og fiskeridepartementet, Oslo. https://lovdata.no/dokument/LTI/forskrift/2020-01-14-63 (Accessed 19 Jun 2020)

Nazir S, Sorensen LJ, Øvergård KI, Manca D (2015) Impact of training methods on distributed situation awareness of industrial operators. Saf Sci 73:136-145

Norwegian Maritime Authority (2012) Rapport om sikkerhet ved bruk av fritidsbåt [Report on safety related to use of leisure boats]. Norwegian Mariitme Authority, Haugesund https:/www.sdir.no/contentassets/cf0 e3401d9884d0881569ab9bd2501b0/rapport-fritidsbater.pdf?t=1577704513639 (Accessed 30 Dec 2019)

Norwegian Maritime Authority (2019) “Løft blikket”. Internet site: https://www.loftblikket.no [Accessed: 28 May 2020]

Øvergård KI (2015) Human error: causality and the confusion of normative and descriptive accounts of human performance. In KI Fostervold, SÅK Johnsen, L Rydstedt and RG Watten (eds) Creating sustainable work environments, Norwegian Society for Ergonomics and Human Factors, Lysaker, pp C5-6 - C5-10

Øvergård KI, Bjørkli CA, Røed BK, Hoff T (2010) Control strategies used by experienced marine navigators: observation of verbal conversations during navigation training. Cogn Tech Work 12(3):163-179

Øvergård KI, Sorensen JS, Nazir S, Martinsen TJ (2015a) Critical incidents during dynamic positioning: operators' situation awareness and decision-making in maritime operations. Theor Issues Ergon Sci 16(4): 366-387 
Øvergård KI, Nielsen AR, Nazir S, Sorensen LJ (2015b) Assessing navigational teamwork through the situational correctness and relevance of communication. Procedia Manuf 3:2589-2596

Øvergård KI, Tannum MS, Haavardtun P, Syversen JKB (2018) Chase, no straighter: COLREG compliant anti-collision manoeuvres for crossing situations. In: Øvergård KI (ed) Robotic sailing 2017. Springer, Cham, pp 81-91

Petersen J (2004) Control situations in supervisory control. Cogn Tech Work 6(4):266-274

Porathe T (2015) Human-machine interaction between unmanned, autonomous, ships and manned nonSOLAS vessels in confined and inshore waters: research needs, In Proceedings of international conference on advanced intelligent maritime safety and technology (12-14 November 2015; Riviera Hotel, Daejeon, Republic of Korea), 5 pages

Reason J (1990) Human error. Cambridge University Press, Cambridge

Reason J (1997) Managing the risks of organizational accidents. Ashgate, Aldershot

Rothblum AM, Wheal D, Withington S, Shappell SA, Wiegmann DA, Boehm W, Chaderjian M (2002) Human factors in incident investigation and analysis. Coast Guard Research and Development Center, Groton

Sjofartsverket.se (n.d.) MONALISA 2.0: securing the chain by intelligence at sea. Horizon2020-project. Available at: http://www.sjofartsverket.se/en/MonaLisa/MONALISA-20/ (Accessed 04 sept. 2019)

Stanton NA, Stewart R, Harris D, Houghton RJ, Baber C, McMaster R, Salmon P, Hoyle G, Walker G, Young MS, Linsell M, Dymott R, Green D (2006) Distributed situation awareness in dynamic systems: theoretical development and application of an ergonomics methodology. Ergonomics 49(12-13):12881311

STM (n.d.) Sea Traffic Management Validation Project, Horizon2020 project. https://www.stmvalidation.eu (Accessed 04 Sept. 2019)

Stoop JA (2003) Maritime accident investigation methodologies. Int J Inj Control Saf Promot 10(4):237-242

Stout RS, Cannon-Bowers JA, Salas E, Milanovich DM (1999) Planning, shared mental models, and coordinated performance: an empirical link is established. Hum Factors 41(1):61-71

Strauch B (2005) Investigating human error: incidents, accidents, and complex systems. Ashgate, Aldershot

Publisher's note Springer Nature remains neutral with regard to jurisdictional claims in published maps and institutional affiliations. 